\title{
Being-in-the-Anthropocene: A Place-Based Understanding of Anthropogenic Climate Change
}

\author{
Kavita Reddy \\ Department of Humanities \\ Simon Fraser University
}

\begin{abstract}
Using Marcuse's reconciliation of Marx's historical material critique of capitalist relationships with a phenomenological approach, this paper aims to develop a better understanding of the conceptualization of reason in the era of anthropogenic climate change. Along with reference to Marx and Freud, Marcuse employs Heidegger's phenomenology in his analysis of the dynamic interrelation between capital and the historical development of civilization, which I argue creates a comprehensive analysis of reason within the context of capitalist technological progress. The intersection of phenomenological analysis and the history of capital creates a moment, through the resurgence of the slumbering potentiality within place, for a radical shift in perspective.
\end{abstract}

\section{Keywords}

Place-based rationality, anthropocene, critical theory

\section{Introduction}

This paper will delve into the implications of reification and fetishism when applied to technological efficiency and instrumental rationality within the context of anthropogenic climate change. Anthropogenic climate change not only confronts biophysical limits, but also highlights the inherent qualitative aspects of place by revealing limitations to the prevailing rationality that shapes experience and forms the basis of contemporary civilization; the common perceptions that underlie civilization now confront material reality, revealing substantial evidence for environmental effects that could result in circumstances beyond human control. A place-based framework demonstrates a social historical manifestation of reality that is developed through human interaction with the environment.

Through the works of Herbert Marcuse, this paper will expand on Marx's critique of 19th century market economy by examining the critique's wider articulation within the contemporary globalized market and its manifestation through the simultaneous transformation of individual consciousness and institutional organization of the social and natural landscape. Marcuse employs Marx's historical material critique of capitalistic relationships towards a deeper understanding of the emergence of technology and the subsequent industrialization of rationality. With reference to Marx and Freud, Marcuse applies a Heideggerian phenomenological analysis to his understanding of the dynamic interrelations that comprise the process of capital accumulation, and he investigates the historical emergence of civilization through its relationship with technology. Grounded in a phenomenological understanding of place, Marcuse's analysis examines the manner in which the organization of place is determined by our engagement with the world, and he explores the developed infrastructure we create that determines the choice of our actions.

Marcuse aims to expand Marx's understanding of fetishism and alienation resulting from capital accumulation to include a discussion of technological domination. In his essay Some Social Implications of Modern Technology (1941), Marcuse aims at investigating the fetish of technical efficiency, and "technology, as mode of production, as the totality of instruments, devices and contrivances which characterize the machine age is thus at the same time a mode of organizing and perpetuating 
(or changing) social relationships, a manifestation of prevalent thought and behavior patterns, an instrument for control and domination" (p.138). When considering anthropogenic climate change, what is required is a critical assessment of the ecological crisis that emphasizes the concept of instrumental rationality in relation to the dynamics of capital accumulation. The aim of this paper is thus to develop a better understanding of the conceptualization of reason in the era of anthropogenic climate change through the critique of instrumental rationality.

Relying on Marcuse and Andrew Feenberg's synthesis, the first section of this paper will explore the modern conceptualization of reason, which operationalizes the subjective perception of the world through a highly instrumental rationality that dominates existence. The modern conceptualization of reason is the result of the collapse of antagonistic plurality into a one-dimensional world premised on alienation. One-dimensionality refers to the loss or suppression of the sensuous, aesthetic dimension where multiplicity thrives with contradictions, breakdowns, and possible ways of being. This one-dimensional world subsumes subversive tendencies into merely quantitative differentiation within a homogenized understanding of being-in-the-world. The analysis constitutes Marcuse's critique of an instrumental rationality that reformulates the idea of progress to domination for wealth creation perpetuated by technological efficiency. Wealth creation embodies an unfettered perpetuation of means that assumes a nihilistic conceptualization of progress, requiring a transformation of the qualitative value of the object and the subject's relationship to the object.

The second section will work through Marcuse's synthesis of historical materialism and its implications examined through a Freudian analysis of libidinal instinctual development. This opens Marcuse's understanding of sensibility to include the internalization of domination, allowing for discussion of the close affinity between instinctual and natural domination. Sigmund Freud, in Civilization and its Discontents, parallels the development of civilization to the development of libidinal instincts in order to demonstrate the mimetic effect between external and internal domination. Marcuse historicizes Freud by tracing the movement and expansion of capital accumulation and the development of civilization through an understanding of surplus repression, resulting in the transformation of satisfaction via repressive de-sublimation. Liberation from these repressive tendencies is achieved through radical change of the democratic populace and its current understanding of freedom as represented in monopoly capitalism.

The final section will sketch an alternative conception of rationality premised on the aesthetic politics of Marcuse; the politics of the beautiful emphasize the historically denied and arrested aesthetic potentialities of place and the historical potentialities that "haunt established society as subversive tendencies and forces" (Marcuse, 1964, p.8). When applied to the ecological crisis of the 21 st century, a Marcusian analysis assists in re-constituting the lost critical faculties of reason and reorientating discussion towards a revolutionary transformation of society's relationship to technology and science. Marcuse's analysis operates through not only an understanding of experiential reality grounded in the aesthetic principles of beauty and sensibility but also through principles of praxis as embodied in Marcuse's Great Refusal. I argue that a Marcuseian analysis transcends the operationalized containment of change embodied in industrialized rationality, and an application of his analysis demonstrates that the perception of anthropogenic climate change is dialectically constrained through the institutional arrangement of technology, politics, and science. The aesthetic dimension as proposed by Marcuse illuminates an understanding of place where basic experience is sensuous rather than conceptual.

\section{The Industrialization of Reason}

At the close of the era, knowledge of essence has primarily the function of building the critical freedom of the individual to pre-given, unconditional valid necessities. It is no longer the 
spontaneity of the concept but the receptivity of intuition that serves as the organ of the doctrine of essence.

Marcuse (1964, p.32)

Marcuse, in his essay The Concept of Essence, explores the metaphysical character of the philosophical conceptualization of essence by examining the sociohistorical roots of thought. Marcuse examines how the historical conceptualization of essence results in an object of thought that is different than an object of immediate experience, and, "if the concept never denotes one particular concrete thing, if it is always abstract and general, it is so because the concept comprehends more and other than a particular thing, which determines the form in which it appeals as a concrete object of experience" (1968, p. 83). Marcuse recalls Plato's early conceptualization of essence as a tension between the ever-changing sensual development of the world we inhabit and the externalized, fixed conception of truth, because it is "in Plato's theory of ideas, where the concept of essence was first clearly formulated, it was an outcome of the quest for the unity and universality of being in view of the multiplicity and changeability of beings" (Marcuse, 1968, p. 33).

Plato, in The Republic, articulates the unwavering potentiality in meaning and being in relation to the changing world:

Our argument indicates that the capacity for knowledge is innate in each man's mind, and that the organ by which he learns is like an eye which cannot be turned from darkness to light unless the whole body is turned; in the same way the mind as a whole must be turned away from the world of change until its eye can bear to look straight at reality, and at the brightest of all realities which is what we call the good (1955, p. 245).

Plato mentions above that the good is in the ability to turn away from the world of change. The implication is that static conceptions of truth are external and prior to experience. Essence, reality, or external truth as outlined by Plato is something beyond and independent of any particular object. In Book Seven of The Republic, Plato establishes an understanding of visible reality acquired through sight as merely a representation, and truth is obtained when looking past the particulars to an unwavering essence so that, "when the mind's eye is fixed on objects illuminated by truth and reality, it understands and knows them, and its possession of intelligence is evident; but when it is fixed on the twilight world of change and decay, it can only form opinion; its visions is confused and its opinions shifting." (Plato, 1955, p. 234) The imagery of the sun is prominent in the simile of the decrepit, dark conditions of a cave juxtaposed with the clear, bright surface representing the ascent into the "brightest of all realties to which is what is called good" (Plato, 1955, p. 245). The conceptualization of reason collectively sketches a tension between knowledge of the unchanging object and the object perceived by the senses. The world of the senses is shown to be ephemerally representational of that which is real, so that "the whole procedure involves nothing in the sensible world, but moves solely through forms to forms, and finishes with the forms" (Plato, 1955, p. 239). In this manner, the capacity for abstract thought becomes constrained to move in one-dimension, rendering evidence from the senses into a vestigial category of being.

The preoccupation with essence, for Marcuse, stems for the need to create unity through truth, and so "much of men's real struggle and desires went into the metaphysical quest for an ultimate unity, truth and universality of being" (Marcuse, 1968, p.31). The implication of Plato's theory of forms is that the established essence of the object as unchangeable or atemporal alters the perception of the object by abolishing the historical and social dynamics of its emergence, and "in philosophy, there are fundamental concepts whose metaphysical character sets them apart from the sociohistorical roots of thought" (Marcuse, 1968, p. 31). The contrast outlined by Plato between the visible and the intelligible demonstrates an early philosophical conceptualization of reason so highly 
influential on thought that Marcuse states, "From Plato on, the ancient theory of essence was impelled by the unrest of the unresolved tension between essence and existence" (Marcuse, 1968, p. 33). The visible-intelligible or existence-essence duality of the object is well entrenched in western philosophical discourse and is exemplified in the modern industrialization of rationality.

In contrast with the Greek conception of techne, modern technology separates means and ends so that "this world is understood mechanistically not teleologically" (Feenberg, 2005, p.12). Marcuse suggests that a reified conception of reality establishes itself a priori to perceived experience, degrading encountered objects in the world to mere system components within an unfettered growth narrative which manifests itself in the organization of material reality, and "when cities and highways and National Parks replace the villages, valleys and forests; when motorboats race over lakes and planes cut through the skies - then these areas lose their character as a qualitatively different reality, as areas of contradiction" (Marcuse, 1964, p.57). Place in this sense embodies an institutional drive reinforcing the perpetuation of instrumental rationality through technological development. Like a highway that guides the traveller through the country, designating points at which one may cautiously enjoy nature from a lookout point with billboards advertising food and lodging nearby, the institutional organization of civilization constrains action to expedite growth of the gross domestic product. Growth of the economy is conceptually linked to personal safety and success to the extent that acting against such hegemonic constructions promises inconvenience, a degraded experience, or even danger.

Through a model of technological revealing as presented in Heidegger's understanding of modern technology, where objects in the word are revealed through the subject's interaction with the object through a process of making, Marcuse proceeds to demonstrate the transformation of rationality in light of modern technology in conjunction with the circulation of capital. Marcuse introduces the conception of instrumental rationality, which operationalizes reason through logic under an apparatus of administration so that, as Marcuse states, "domination is transfigured into administration" (Marcuse, 1964 p. 33). Instrumental rationality precipitates a perception of both labor and nature as raw material within the grand scheme of exchange premised on the accumulation of surplus. Capital formalizes logic through technologically efficient use of means, qualitatively transforming being-in-the-world so that "containment of social change is perhaps the most singular achievement of advanced industrial society" (Marcuse, 1963, p. 9). This is the result of a highly operationalized technical reality mimicking an external truth that discounts material and social limitations.

The implication of modern technology is not inevitable destruction through catastrophic nuclear warfare, rampant machine intelligence, and climate change; rather, as stated by Andrew Feenberg, the danger resides in the potential "obliteration of humanity's special status and dignity as the being through whom the world takes on intelligibility and meaning" (Feenberg, 2005, p.14). Modern technology truncates possibilities of the object, which is to say that the object is always already forced to correspond to a new, primary significance that was previously one of many. One set of definite qualities is chosen without subsequent critical engagement, marooning the object in one reality. However, potential ways of being can be rediscovered despite what Plato implied about the Theory of Forms. Essence is shown to be a social construction that can be dissolved. The examination of essence through Marcuse demonstrates history as a progression of abstractions extant for their utility in decoupling material from its origin for the purpose of accumulating capital.

Technological domination traced from Marx's fetishism and alienation to its results in contemporary society can be observed in the commercialization of the university. Frederick Taylor, the author of The Principles of Scientific Management published in 1911, claimed the application of his self-evident principles, deemed scientific rather than heuristic (rule-of-thumb), would induce such great gains in efficiency that the employer and employee would achieve a state of permanent maximum prosperity. For Taylor, "the greatest prosperity can exist only when that individual has 
reached his highest state of efficiency; that is, when he is turning out his largest daily output."1 Elton Mayo of the Harvard Business School took up the study of productivity with dubious methodological rigor, concluding that a new type of interpersonal dynamics in the workplace premised on identification with the team, free expression, and common purpose could generate meaning and increase productivity. In relation to the industrial apparatus that manages human concerns, Mayo concluded that, "so long as commerce specializes in business methods which take no account of human nature and social motives, so long may we expect strikes and sabotage to be the ordinary accompaniment of industry". 2

Taylor and Mayo contribute to the continuing dialectic between rationalism and humanism, and their work has become the basis of scientific management theory taught in universities. The result is a proliferation of both systems engineering and human resources literature that appears to legitimize humans in machine-like processes and the containment of social change though scientificsounding language. The ethic of efficiency is internalized while claims of a flattening bureaucracy placate the revolutionary urge through the appearance of egalitarianism, perpetuating the illusion that bureaucracy's end will come with the next innovation. Management theory becomes a means to provide evidence for truths the owners of production need to be true in order to perpetuate the narrative of legitimacy and continuity. Inducing workers to share goals with employers, like community resilience or protecting the environment, provides misdirection from mechanical toil as exploitation to a loftier common theme. As these ideas pervaded industry, they pervaded the university itself, driving efficiency in the context of neoliberalism both for the market value of the skills acquired by the students and the degree of organizational sophistication for efficiency of the university administration. The university prunes the portions of itself that the market does not value, resulting in defunded humanities departments in favor of growing administration at the expense of teachers and students. This results in diminishing the number of individuals able or willing to question orthodoxy and develop critical faculties in an institutional setting. Thus, the critical faculty of reason and the ability to engage with the sensuous realm as described by Marcuse is neglected in society, leaving instrumental rationality unopposed to flourish.

\section{Historical Materialism and the Destructive Dialectic between Nature and Self}

As understood by Heidegger and Marcuse, meaning within ancient Greek civilization retains an understanding of intrinsic value. However, an implication of value-neutral modern technology is that its effects can be re-appropriated within an externalized framework of reason. When coupled with the formalized law of the market, instrumental rationality sheds any quality capital's valorization process is unable subsume as though "everything is exposed to an analytical intelligence that decomposes into useable parts" (Feenberg, 2005, p.8). Modern technology and its concomitant alienation results in homogenization of not only the natural elements of place but also the individual consciousness. This homogenization intimately connects natural and social domination through "the scientific method which came to provide the pure concepts as well as the instrumentalities for the ever more effective domination of man by man through the domination of nature" (Marcuse, 1964, p.115). Alienation manifested through the decoupling of humanity and nature is not opposed but tolerated and even celebrated by identification with the employment of science and technology within a system of rationalized domination:

We live and die rationally and productively. We know that destruction is the price of progress as death is the price of life that renunciation and toil are the prerequisite for gratification and

${ }^{1}$ http://www.gutenberg.org/cache/epub/6435/pg6435-images.html

${ }^{2}$ http://www.library.hbs.edu/hc/hawthorne/04.html\#four 
joy, that business must go on and that alternatives are utopian. This ideology belongs to the established societal apparatus; it is a requisite for its continuous functioning and part of its rationality.

Marcuse (1964, p.149)

In his essay Foundation of Historical Materialism (1932), Marcuse works through Marx's 1844 Economic and Philosophic Manuscripts to reveal the sensual relationship between labor and nature that has become estranged through the historical manifestation of the political economy. Estrangement within a highly rational world is perpetuated by the loss of active sensibility to the objects encountered in the world. In relation to the world, the individual is both a natural being and an objective being to the extent that being emerges among the relationships to real objects outside of itself to construct a world. Within and through transformation and appropriation of objects, being modifies nature and its own life. In this sense, life is a matter of creating and being created by objects posited by other objects ad infinitum situated within place, and this is the fundamental connection of being to sensuousness for Marcuse as represented in Marx: interaction with objects requires use of the senses. However, because this objective world resides outside of the individual, "it makes it possible for man completely to 'lose' the object as part of his essence and let it become independent and overpowering. This possibility becomes a reality in estranged labour and private property" (Marcuse, 2007, p.86).

Human perception grounded in sensuousness is either passive or actively receptive, which is determined largely through the relationship with the objective world characterized by the degree of separation and loss of the object as part of the essence or affinity in confrontation with it through labor. Ultimately, the ability to retain the matter of human essence and the degree to which the object is lost is embodied in labor and its relationship to nature. An individual fully engaged with the objective world requires insight into "how and through what man and his objective world as social relations have become what they are" (Marcuse, 2007, 100). A highly estranged objective world creates a distance between the individual and the objective world of their creation, resulting in passive rather than active sensuous free activity. The domination of nature through the commodification of both land and labor power coupled with the lack of ownership that is a result of this relationship results in the domination of the individual within civilization.

Marcuse merges Marx's critique of political economy with a Freudian model of psychosomatic libidinal dynamics to demonstrate, through a socio-historical reconciliation of the movement of capital and individual consciousness, how capital accumulation results in and requires the surplus repression of individual libidinal instincts. An understanding of the development of civilization alongside capital accumulation introduces a growing repressive tendency:

As psychology tears the ideological veil and traces the construction of the personality, it is led to dissolve the individual: his autonomous personality appears as the frozen manifestation of the general repression of mankind. Self-consciousness and reason, which have conquered and shaped the historical world have done so in the image of repression internal and external and reveals the power of the universal in and over the individual.

Marcuse (1974, p.86)

Human beings are naturally dominated by the interest of satisfying needs, which is a source of repression. Basic repression is an inherent part of the human psyche, because human being are forced to repress their own libidinal instincts in order to survive in this world by delaying gratification, and "the repressive modification of the instincts under the reality principle is enforced and sustained by the external primordial struggle for existence ... scarcity teaches men that they cannot freely gratify their instinctual impulses, that they cannot live under the pleasure principle" (Marcuse, 1974, p. 45). However, Marcuse argues that the social organization of capitalism has resulted in 
surplus repression through a systematic perpetuation of scarcity premised on the unequal distribution of resources, and "throughout the recorded history of civilization, the instinctual constraints enforced by scarcity have been intensified by hierarchal distribution of scarcity and labor; the interest of domination added surplus repression to the organization of the instincts under the reality principle" (Marcuse, 1974, p. 75). Surplus repression is maintained through the systematic perpetuation of capitalism, which results in repressive de-sublimation within a technical society that quells meaningful refusal of the surplus repression. This is achieved through arresting and diverting potentialities of instinctual energy expenditure, which reinforces one-dimensional thinking, and "the psychoanalytic interpretation reveals that the reality principle enforces a change not only in the form and timing of pleasure but in the very substance - a de-sublimation" (Marcuse, 1974, p. 39).

The reality principle and its repressive tendencies materialize within institutional systems resulting in manipulation of instinctual energy or institutionalized de-sublimation. Within this system desired skills and behaviors are reinforced through the systematic division of labor and pleasure so "repression disappears in the grand objective order of things which rewards more of less adequately the complying individuals and in doing so, reproduces more or less adequately society as a whole" (Marcuse, 1974, p. 78). Surplus repression and de-sublimation are justified through a highly rationalized and operationalized system that defines civilization. The increasingly efficient and abundant world of contemporary civilization has resulted in the marginalization to absence of demonstrable, unrestricted agents of social change and a quelled, obedient nature available for domination without protest. Contemporary civilization has resulted in the creation of an impotent agent and a mute ecosystem because these components are subsumed in a one-dimensional world of value expansion, revealing the perpetuation of instrumental rationality through technological means that leads to the administration of things rather than of people and place.

In Civilization and Its Discontents, Freud demonstrates the development of civilization alongside the instinctual libidinal dynamics of the individual, and Marcuse employs this model to demonstrate that "what shapes the instincts as well as their needs and satisfaction is a socio-historical world" (Marcuse, 1974, p. 39). Marcuse historicizes Freud in Eros and Civilization and states that, "according to Freud, the history of man is the history of repression. Culture constrains not only his societal but also his biological existence, not only parts of the human but his instinctual structure" (Marcuse, 1974, p. 35). According to Freud, we stabilize the anxiety perpetuated by civilization by subduing natural and social threats to our well-being; however, this results in a destructive dialectic to the extent that we create and maintain the very things that continue to repress our instinctual structures, shaping a history of progress that is simultaneously a history of social and natural domination:

The entire progress of civilization is rendered possible only by the transformation and utilization of the death instinct or its derivatives. The diversion of primary destructiveness from the ego to the external world feeds technological progress and the use of the death instinct for the formation of the superego achieves punitive submission of the pleasure ego to the reality principle and assures civilized morality.

Marcuse (1974, p. 83)

In a lecture given by Marcuse entitled Ecology and the Critique of Modern Society, the ego's primary destructiveness is paralleled to the destructive tendencies toward nature when he states:

The specter, which haunts advanced industrial society today, is the obsolescence of full time alienation. The death and destruction instinct strives to attain a negation of life though externalization. That means that this drive is directed away from the individual. It is directed to life 
outside the individual. The drive is externalized. It is directed towards the destruction of the other living things, of other living beings and of nature.

Marcuse (1992, p. 35)

The destructive dialectic is a consequence of alienation, humanity's predisposition to valorize external objects through pattern recognition, and the resultant perceptions govern life with little further interaction. The commodity form premised on exchange confronts the individual, subordinating them to objectively imposed laws that dictate social life. The world of commodities appears as if produced by an obscured daemon so that "the pain, frustration, impotence of the individual derive from a highly productive and efficiently functioning system in which he makes a better living than ever before" (Marcuse, 1974, p. 143). The object lost from essence becomes value-neutral technology continually re-appropriated for satisfying needs and subduing threats due to heterogeneous distribution of scarcity, directing the instinct for destruction at nature. This ideology of advanced industrial society results in a self-reproducing autonomous system that subjugates the individual.

\section{The Politics of the Beautiful: A Place-Based Understanding}

I argue that the advent of capitalism introduced the most effective and all-encompassing rationalization by self-propagating a rift between humanity and nature. The all-encompassing nature of the rationalization is even more pernicious in that it alters the notion of existence to limit the space of freedom and even "the longing, the need for such an environment" (Marcuse, 1974, p.18). However, through an understanding of aesthetics, Marcuse evokes the potentialities within sensual, experiential reality. Incorporating a phenomenological understanding of meaning emergent from the subject's experience and the consequences to the ecosystem and society resulting from the exploitative conditions of instrumental rationality, Marcuse determines a relationship between subject and the world encountered through action directed at meaningful objects. Marcuse writes, "The philosophical effort to mediate, in the aesthetic dimension, between sensuousness and reason thus appears as an attempt to reconcile the two spheres of the human existence which were torn asunder by a repressive reality principle" (Marcuse, 1974, p. 242). Meaning for Marcuse emerges from the individual at the site of experience with external (and internal) sensual objects, not with raw material, but "the laws of reason must be reconciled with the interest of the senses" (Marcuse, 1974, p. 254). I argue such an understanding illuminates the resurgence of a place-based ethics, such as grounded normativity brought forth by Glen Coulthard. The similarity between Marcuse's aesthetics theory and grounded normativity is that that they suggest alternatives to being-in-the-world by emphasizing the qualitative aspects of sensual, experiential reality rather than reality understood after the conceptualization of essence. Essence and existence are not enshrined in static conceptions of truth but in a constant process of revealing, and "things do not have fixed essences, rather they belong to a field of interactions which establishes their inner coherence and their boundaries. These interactions are a source of tensions that drive things forward toward their developmental potentialities" (Feenberg, 2005, p. 25).

First Nations resistance to colonial powers embodies such an alternative to the rationality of capitalism, because their demands for recognition are based primarily on their ability to maintain a relationship premised on grounded normativity that runs contrary to predatory capitalist imperatives. Grounded normativity highlights a relationship between human civilizations and nature founded on reciprocity with nature rather than a model that dominates and ascribes value to land and the operations on it for profit. Coulthard reinforces this point by recounting a statement by Dene Elder, Philip Blake:

We have lived with the land, not tried to conquer or control it or rob it of its riches. We have not tried to get more and more riches and power, we have not tried to conquer new frontiers, 
or out do our parents, or make sure that every year we are richer than the year before. We have been satisfied to see our wealth as ourselves and the land with live with.

$$
\text { Coulthard (2014, Loc. 1412) }
$$

In this sense, human civilization can interact with nature in an indefinitely self-sustainable manner premised on use rather than exchange. Humanity's relationship with nature can be considered nonexclusionary to the extent that co-existence is reinforced between nature and human civilization when implicit awareness of the consequences emanating from the interactions with nature informs human civilization's actions. Similarly for Marcuse, "the basic experience in this dimension is sensuous rather than conceptual. Aesthetic perception is essentially intuition not notion. Nature of sensuousness is receptivity, cognition through being affected by given objects" (Marcuse, 1974, p. 238). Marcuse expands the sensual reality to include the structure of beauty and freedom, which are both grounded in the primary instincts and assume the harmonious union of sensuousness imagination and reason as they release potentialities of man and nature. Feenberg notes that, "according to Marcuse, aesthetic form is a kind of reduction and idealization that reveals the true essence of things sensuously, things as they would be redeemed in a better world. Form is active in sensation as well, giving rise not only to appreciation of beauty but also to a critical repulsion towards all that is life destroying and ugly" (Feenberg, 2010, p. 205). Marcuse and Coulthard in this sense aim at engaging experiential reality, liberating possibilities, and adhering to material limits.

As outlined by Marcuse, the understanding of aesthetics as beauty and imaginative play are not conceptions that are simply introduced into radical political judgment, but aesthetics, as Feenberg states, "describes the a priori from of a new type of experience belonging to a new social order" (Feenberg, 2005, p. xiii). Marcuse's critique of the principle tenets of critical theory as outlined in An Essay on Liberation is their predisposition to "deprive utopia of its traditional unreal content: what is denounced as utopia is no longer that which has no place and cannot have any place in the historical universe, but rather that which is blocked from coming about by the power of the established societies" (1969, p. 9). The denial of utopia results in a change that remains within the confines of one-dimensionality. as outlined by Marcuse, the Great Refusal requires instead forceful dismantling of the relationships that comprise civilization to break the cycle of domination, and "the revolution must be at the same time a revolution in perception which will accompany the material and intellectual reconstruction of society, creating a new aesthetic environment" (Marcuse, 1969, p. 30). This act is definitive and energetic, and the demands are developed in the course of action in the political realm. Decomposing the edifice of administration necessitates a change in the very biology of the individual to integrate objects so that "the essences of things are no longer reified as things themselves but understood from out of their place in everyday practical activity, phenomenologically interpreted" (Marcuse, 1969, p. 28). Self-liberation is not violent but transformative to a being that is free, and radical subjectivity means to modify the "instinctual needs, different reactions to the body as well as the mind," (Marcuse, 1969, p. 17) to struggle for a form of existence without the need for anxiety. The conditions of production can be made to render the existing instincts so successful for domination maladaptive and, therefore, superfluous. These changes are necessary because exploitation is not merely caused by modern technology and capital accumulation but by the order of sensibility and rationality: institutional and technological de-sublimation. Change in the Marcusian sense also means purposefully crafting the environment in which we interact:

The new sensibility has become, by this very token, praxis: it emerges in the struggle against violence and exploitation where this struggle is waged for essentially new ways and forms of life: negation of the entire Establishment, its morality, culture; affirmation of the right to build a society in which the abolition of poverty and toil terminates in a universe where the sen- 
suous, the playful, the calm, and the beautiful become forms of existence and thereby the Form of the society itself.

Marcuse (1969, p. 25)

This new sensibility as outlined by Marcuse is extremely pertinent to the ecological movement of the early $21^{\text {st }}$ century to the extent that it mobilizes groups of individuals from all facets and classes of life to advocate for a new way of being. This action is met with solidarity and premised on freedom through a change in perception and rationality currently contained by the dominating hold of capital. Marcuse attests to this when commenting on the environmental movement: "The ecology movement reveals itself in the last analysis as a political and psychological movement of liberation. It is political because it confronts the concerted power of big capital, whose vital interests the movement threatens. It is psychological because the pacification of external nature, the protection of life environment, will also pacify nature within men and women" (Marcuse, 1992, p. 36).

In the 2012 documentary Chasing Ice, director Jeff Orlowski documents National Geographic photographer James Balog during his assignment to capture climate change through a multiyear chronicle of the Earth's rapidly melting glaciers. Jeff Balog, initially pursuing a Masters degree in geomorphology, switched from science to photojournalism in order to pursue a more direct connection with the natural world. Balog's photography is reminiscent of Marcuse's relationship to aesthetics and the ability of art to reshape our perceptions of the world. In the Essay on Liberation, Marcuse states: "as such a force, art would be an integral factor in shaping the quality and the appearance of things, in shaping the reality, the way of life." (1969, p. 27). Balog achieves this by producing provocative images of the immense yet frangible glaciers to evoke the tension between the huge enduring power of a glacier and its fragility. Paraphrasing Balog, the public does not want more statistical studies, computer models, or projections; rather, they need believable, understandable visual evidence with visceral appeal. ${ }^{3}$ The public needs to be engaged by experiencing a monolith of ice fracturing in order to point directly at the ecological limits to capitalism. The images depict violent rifts in seemingly eternal units of nature and expose the mystifying characteristics of the ecosystem, promising changes of unknown magnitude to our existence. In this sense, Balog captures the dialectic between human activity and nature while he captures the historical memories of the landscape through photography.

The analysis of this history in relation to the landscape depicts the instability of the Arctic climate, which is a presentation that has become increasingly necessary as a representative of all risk to the biosphere; the implications of rapidly melting permafrost and ice for our civilization are overshadowed by the potential for more efficient shipping lanes and reduced barriers to underwater drilling for oil extraction. Industrialization puts pressure on sensitive, globally-connected ecosystems, yet the political mandate is currently focused on state control of the circumpolar region to secure resources to increase the capacity of industrialization, which is exactly the opposite of addressing the oceanic and atmospheric temperature increase causing ecosystems to be pressured. Discussion continues among members of the Arctic Council regarding sovereignty of the claimed Arctic Ocean floor territories through the establishment of the continental shelf as a frontier. James Balog argues that anthropogenic climate change is not only a matter of politics, technology, or science but also a matter of perception that is de-contextualized from the everyday institutional organization that normalizes and constrains action within the destructive dialectic between human labor and nature. His photography offers an example of a placed-based understanding by adhering to the sensual, material limits and perceptions dictated by the historical development of civilization on the land.

${ }^{3}$ http://www.springfieldspringfield.co.uk/movie script.php?movie=chasing-ice 
The world, according to Marcuse is revealed as raw, boundless material and energy to no end because of the conceptualization of modern rationality. Surplus repression perpetuated through instrumental rationality results in the impotent agent and the mute ecosystem, constraining society into one dimension where aesthetic form is subdued and diverted. Instrumental rationality, tracing from the concept of essence, collapses possible states so that a rift between humanity and nature is the only remaining outcome, resulting in a self-propagating, mechanized system of domination that has planetary-scale effects on life, climate, oceans, and geology: the Anthropocene. The alternatives to instrumental rationality necessitate closure of every mutilated material feedback loop between the human population and the ecosystems that support it. Like Heidegger's broken hammer, breakdowns in the Anthropocene era signal decomposition of the monolithic understanding of being-inthe-world into being-in-place.

\section{References}

Coulthard, G. (2014). Red skin, white masks: Rejecting the colonial politics of recognition. Minneapolis: University of Minnesota Press.

Feenberg, A. (2005). Heidegger and Marcuse: The catastrophe and redemption of history. New York: Routledge.

Feenberg, A. (2010). Between reason and experience: Essays in technology and modernity. London: The MIT Press.

Marcuse, H. (1941) "Some Social Implications of Modern Technology. In A. Arato \& E. Gebhardt (eds.), The essential Frankfurt school reader (pp. 138-163). New York: Continuum.

Marcuse, H. (1969) An Essay on Liberation. Boston: Beacon Press Books.

Marcuse, H. (1964). One-Dimensional Man. Boston: Beacon Press books.

Marcuse, H. (1968). Negations: Essays in Critical Theory. (Jeremy J. Shapiro, Trans). London: Penguin Press.

Marcuse, H. (1974). Eros and Civilization: A Philosophical Inquiry into Freud. Boston: Beacon Press books.

Marcuse, H. (1972). Studies in Critical Philosophy. Boston, Beacon Press.

Marcuse, H. (1992). "Ecology and the critique of modern society." Capitalism, Nature, Socialism, $3(3), 19-29$.

Orlowski, J. (Producer), Monroe, Mark. (Writer). (2012). Chasing ice. United States of America: Submarine Entertainment.

Plato. (1955). The Republic. (D. Lee, trans.). London: Penguin Classics. 